\title{
Do Mendeley Reader Counts Indicate the Value of Arts and Humanities Research? ${ }^{1}$
}

Mike Thelwall, University of Wolverhampton, UK

Abstract

Mendeley reader counts are a good source of early impact evidence for the life and natural sciences articles because they are abundant, appear before citations, and correlate moderately or strongly with citations in the long term. Early studies have found less promising results for the humanities and this article assesses whether the situation has now changed. Using Mendeley reader counts for articles in twelve arts and humanities Scopus subcategories, the results show that Mendeley reader counts reflect Scopus citation counts in most arts and humanities as strongly as in other areas of scholarship. Thus, Mendeley can be used as an early citation impact indicator in the arts and humanities, although it is unclear whether reader or citation counts reflect the underlying value of arts and humanities research.

Keywords: Mendeley; altmetrics; scientometrics; arts; humanities; research evaluation

\section{Introduction}

Citation counts routinely support research evaluations in many areas of science but tend to be avoided in the arts and humanities for several reasons. Most fundamentally, whilst there are reasons to believe that in hierarchical sciences citations tend to be used to acknowledge influential prior work (Merton, 1973), in non-hierarchical subject areas this seems to be less likely. Arts and humanities scholars may cite works that sparked creativity in unrelated areas, such as by suggesting new approaches (Delgadillo \& Lynch, 1999; Martin \& QuanHaase, 2016) or combinations (Cobbledick, 1996). Humanities outputs are also cited in types of document, such as books, that are not present or underrepresented in major citation indexes (Nederhof, 2006; for references, see also: Larivière, Archambault, Gingras, \& Vignola-Gagné, 2006). Moreover, in the arts and humanities, monographs and artworks tend to be more important than journal articles, and fields that legitimately target a national audience give value that is poorly reflected through international citation indexes (Hicks, 2004; Nederhof, Zwaan, De Bruin, \& Dekker, 1989). Monographs are difficult to evaluate with citation counts because they lack the subject categorisation that journal articles inherit from the journals that they are published in. They may also target a general rather than a scientific audience (e.g., Zuccala \& Guns, 2013).

In terms of empirical evidence of the value of citations, counts of citations to arts and humanities journal articles correlate only weakly with expert judgements. For articles published in 2008 and submitted for evaluation by UK Academics to REF2014, Spearman correlations between expert ratings and Scopus citations for units of assessment that included a substantial amount of arts and humanities content were 0.3 (Anthropology and Development Studies; Communication, Cultural and Media Studies, Library and Information Management), 0.2 (Politics and International Studies; Education; Modern Languages and Linguistics; History), 0.1 (Law; Sociology; Area Studies), 0.0 (English Language and Literature; Art and Design: History, Practice and Theory; Music, Drama, Dance and Performing Arts), -

\footnotetext{
${ }^{1}$ Thelwall, M. (in press). Do Mendeley reader counts indicate the value of arts and humanities research? Journal of Librarianship \& Information Science.
} 
0.1 (Classics, Philosophy), and -0.2 (Theology and Religious Studies) (HEFCE, 2015). In contrast, the correlations for the natural and medical sciences were in the range 0.4-0.7. The REF2014 categories were relatively broad, which undermines the power of correlation tests to identify relationships between citation counts and peer judgements in the narrow fields for which they are most appropriate (Waltman, van Eck, van Leeuwen, Visser, \& van Raan, 2011; Thelwall, 2016b). Thus, in the arts and some humanities, there is some evidence that citation counts are useless for research evaluation but in areas with a social sciences component they may have some value.

The main reason for the apparent weakness of citation counts as indicators of quality in the arts and humanities may be that quality has a different meaning in the arts and humanities. In hierarchical science fields, it is almost self-evident that supporting future research is a good thing and therefore counting the citations that frequently acknowledge this gives an intuitively reasonable quality indicator. This is also why quality and scientific impact are sometimes conflated in the sciences. Nevertheless, quality is a subjective concept. In non-hierarchical arts and humanities subjects, influencing future research is not necessarily good or a primary goal. Instead, arts and humanities outputs may be judged as high quality if they are useful to, or highly regarded by, a given audience (e.g., Thelwall \& Delgado, 2015) (especially if that audience is respected by the judges), or if they demonstrate virtuosity, expertise, "intellectual and theoretical underpinning" (Earnshaw, Liggett, \& Excell, 2015) or another valued personal attribute. These quality judgments are likely to be influenced by external pressures (e.g., government funding) and to change over time. For example, high quality work in one era may be regarded as esoteric in another, when applications, economic worth or educational value are more important (see also: Belfiore \& Upchurch, 2013). There are also many examples from the arts and literature where paintings and novels have been acknowledged as masterpieces after the death of their creators.

Despite the evidence that citation counts have little or no value in the arts and humanities (e.g., the very low correlations between peer judgements and citation counts in Table A3 of: HEFCE, 2015), an article must be read to have any use value at all and so it is logical to assess whether usage data, such as Mendeley readership counts, could better reflect quality or impact. In the context of the altmetrics goal to use mentions or research in the social web to get early and wider impact indicators (Priem, Taraborelli, Groth, \& Neylon, 2010), Mendeley reader counts are the most promising because in science generally they are more numerous (Erdt, Nagarajan, Sin, \& Theng, 2016) except perhaps for tweet counts (Haustein, Larivière, Thelwall, Amyot, \& Peters, 2014), and appear before citations (Maflahi, \& Thelwall, 2016; Zahedi, Costas, \& Wouters, 2015). This is supported by two focused investigations. Few humanities journal articles are mentioned in other social web sources, at least in Sweden (Hammarfelt, 2014), and Korean arts and humanities research is better covered by Mendeley than other subject areas (Cho, 2017).

The academic reference manager Mendeley (Gunn, 2013; Vargas, Hristakeva, \& Jack, 2016) is a free service that helps users to record their references and generate reference lists for their papers. Members usually register articles that they have either read or intend to read and so the number of Mendeley readers of articles is a readership indicator (Mohammadi, Thelwall, \& Kousha, 2016). The data is restricted to users of Mendeley, which tend to be a younger (Mohammadi, Thelwall, Haustein, \& Larivière, 2015) and internationally biased (Fairclough \& Thelwall, 2015ab) sample of all readers. Because students form a substantial minority of Mendeley users (Maleki, 2015; Mohammadi, 
Thelwall, Haustein, \& Larivière, 2015; Pooladian \& Borrego, 2017) and may use it for their assignments (Basri \& Patak, 2015), it is possible that Mendeley reader counts could partly reflect the educational value of articles, although there is no evidence for this yet (Thelwall, in press)

Using the same REF2014 dataset as above, correlations between peer judgements and Mendeley reader counts were 0.2 (Art and Design: History, Practice and Theory), 0.1 (Sociology; Anthropology and Development Studies; History; Communication, Cultural and Media Studies, Library and Information Management), 0.0 (Law; Politics and International Studies; Education; Area Studies; Modern Languages and Linguistics; English Language and Literature; Classics; Philosophy; Theology and Religious Studies), and -0.1 (Music, Drama, Dance and Performing Arts). As for citation counts, the power of the correlations is undermined by the broad categories. Moreover, the relatively early year of the articles selected for analysis, 2008, further undermines the correlation test for Mendeley because more recent articles are more likely to be registered in the site (Thelwall \& Sud, 2016) and even recently published articles may have Mendeley readers (Maflahi, \& Thelwall, 2016). There are other reference managers, such as Bibsonomy (Borrego \& Fry, 2012; Zoller, Doerfel, Jäschke, Stumme, \& Hotho, 2016), but these are substantially less used or do not publish their reader count data.

One previous study has assessed the extent to which citations correlate with Mendeley readers in the humanities with data from 2008. Using Web of Science categories, it found correlations of 0.3 (Linguistics) or 0.2 (Philosophy; History; Literature; Religion) (Mohammadi \& Thelwall, 2014). Thus, with the same broad subject area and publication year caveats as above, it seems that citation counts and Mendeley reader counts have weak correlations with each other. From the increased uptake of Mendeley since 2008, this correlation seems likely to be stronger for more recent data. Moreover, Mendeley reader counts may be substantially larger than Scopus citation counts for recent arts and humanities articles because Scopus does not have extensive arts and humanities coverage for counting citations. Thus, evidence that there were substantially more Mendeley readers than Scopus citations in any area would suggest that Mendeley could identify impacts in education or academia that would not be reflected in citation counts. This would partially support a claim for the value of Mendeley reader counts as impact indicators. The purpose of the current article is to assess these hypotheses with journal article data from Scopus and Mendeley for arts and humanities subject areas.

1. How does the magnitude of the correlation between Mendeley reader counts and Scopus citation counts change over time for arts and humanities fields?

2. How does the difference between the total number of Scopus citations and the total number of Mendeley readers change over time for arts and humanities fields?

\section{Methods}

All twelve narrow subcategories of the Arts \& Humanities broad Scopus category were chosen for analysis: History; Language and Linguistics; Archeology (arts and humanities); Classics; Conservation; History and Philosophy of Science; Literature and Literary Theory; Museology; Music; Philosophy; Religious Studies; Visual Arts and Performing Arts. Narrow categories are important to maximise the power of a correlation test (Thelwall, 2016b).

All documents of type journal article for each year 2007-2017 for each of the above categories were downloaded from Scopus in June 2017 and their Mendeley reader counts were extracted from the Mendeley API with Webometric Analyst (lexiurl.wlv.ac.uk) also in 
June 2017. For nine of the year/subject combinations there were more than 10,000 articles, the Scopus maximum. In these cases, the first 5000 and last 5000 from the year were downloaded instead of the complete set. Since time is the key factor and these are time balanced sets, this should not affect the results. This affected History (2011-2013, 2016), Language and Linguistics (2012, 2013, 2016), Literature and Literary Theory (2013) and Philosophy (2013).

Scopus articles were matched with Mendeley records using a DOI search and a metadata search of Mendeley, combining the results for the most substantial coverage (Zahedi, Haustein, \& Bowman, 2014). The years 2007-2017 were chosen to show trends for recent articles, starting from before the year (2008) investigated by previous studies. Although it is normal in citation analysis to allow several years to elapse before analysing the impact of articles, typically with the aid of a three-year citation window (e.g., Glänzel \& Thijs, 2004; but see: Wang, 2013), the primary value of Mendeley reader counts is to give early impact evidence and so it is useful to include even articles from the data collection year. Whole counting rather than fractional counting (e.g., Waltman, \& van Eck, 2015) is used because publications are not separated by origin (e.g., author, institution).

Since both citation and readership data are highly skewed (median and mode close to zero but some very high values), geometric means are more appropriate than arithmetic means. The standard transformation of prior adding 1 to all values was used for both citation and reader counts to accommodate zeros so the formula used for articles with reader (or citation) counts $r_{1}, r_{2}, \ldots r_{n}$ was:

$$
\breve{r}=\exp \left(1 / n \sum_{i=1}^{n} \ln \left(1+r_{i}\right)\right)-1
$$

Confidence intervals for the geometric mean were calculated by assuming that the logged values $\ln \left(1+r_{i}\right)$ were normally distributed and using the standard normal distribution formula on these, transforming the limits $l_{95}$ and $u_{95}$ with the exponential function afterwards, giving $\exp \left(l_{95}\right)-1$ and $\exp \left(u_{95}\right)-1$. The normal distribution assumption is not true due to high kurtosis from the discrete data, especially when the median is zero, and so the confidence intervals are only indicative.

\section{Results}

The Spearman correlations between Mendeley reader counts and Scopus citation counts were mostly moderate or high after ten years in 2007 (Table 1). Other than Classics (0.384) and Literature and Literary Theory (0.382), the remaining correlations are above 0.5 , and so all could be described as "medium" (about 0.3) or "high" (0.5 and above) (Cohen, 1988), although these interpretations are grounded in psychology research and no not necessarily apply elsewhere (Hemphill, 2003). 
Table 1. Fields, sample sizes and descriptive statistics.

\begin{tabular}{|l|r|r|r|r|r|}
\hline Field & $\begin{array}{l}\text { Minimum } \\
\text { articles } \\
\text { per year }\end{array}$ & $\begin{array}{l}\text { Average } \\
\text { articles } \\
\text { per } \\
\text { year }\end{array}$ & $\begin{array}{l}\text { Readers } \\
\text { /citations } \\
\text { correlation } \\
\mathbf{2 0 0 7}\end{array}$ & $\begin{array}{l}\text { Geomean } \\
\text { citations } \\
\mathbf{2 0 0 7}\end{array}$ & $\begin{array}{l}\text { Geomean } \\
\text { readers } \\
\text { 2007 }\end{array}$ \\
\hline Archeology (arts and humanities) & 1599 & 2735 & 0.707 & 2.2 & 1.8 \\
\hline Classics & 450 & 853 & 0.384 & 1.2 & 0.5 \\
\hline Conservation & 431 & 792 & 0.729 & 1.4 & 1.9 \\
\hline History & 7263 & 8665 & 0.622 & 2.2 & 2.1 \\
\hline History and Philosophy of Science & 1131 & 2722 & 0.779 & 6.1 & 7.9 \\
\hline Language and Linguistics & 4748 & 7492 & 0.815 & 4.2 & 5.5 \\
\hline Literature and Literary Theory & 4352 & 7090 & 0.382 & 0.6 & 0.4 \\
\hline Museology & 248 & 408 & 0.727 & 1.2 & 1.4 \\
\hline Music & 934 & 1547 & 0.673 & 1.4 & 1.6 \\
\hline Philosophy & 4295 & 6962 & 0.634 & 2.8 & 3.3 \\
\hline Religious Studies & 2412 & 4274 & 0.512 & 1.3 & 1.3 \\
\hline Visual Arts and Performing Arts & 2747 & 5106 & 0.477 & 0.5 & 0.4 \\
\hline
\end{tabular}

As has been found previously for other subject areas, correlations between Mendeley reader counts and citation counts increase over time rapidly initially, eventually stabilising. Classics is the exception since it does not stabilise. The correlations for the remaining subject areas stabilise after 3-7 years.

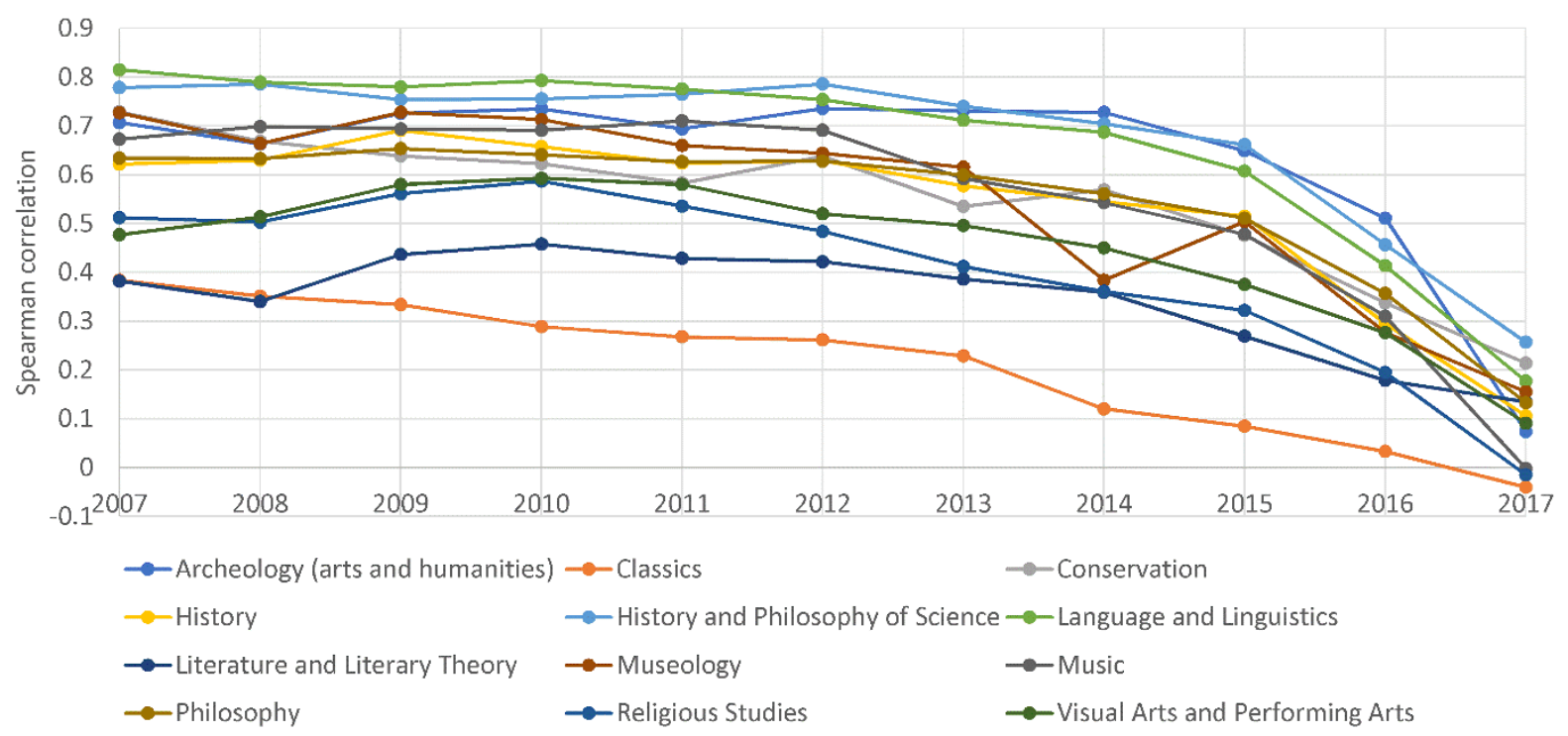

Figure 1. Spearman correlations between Mendeley reader counts and Scopus citation counts for each field and year. 


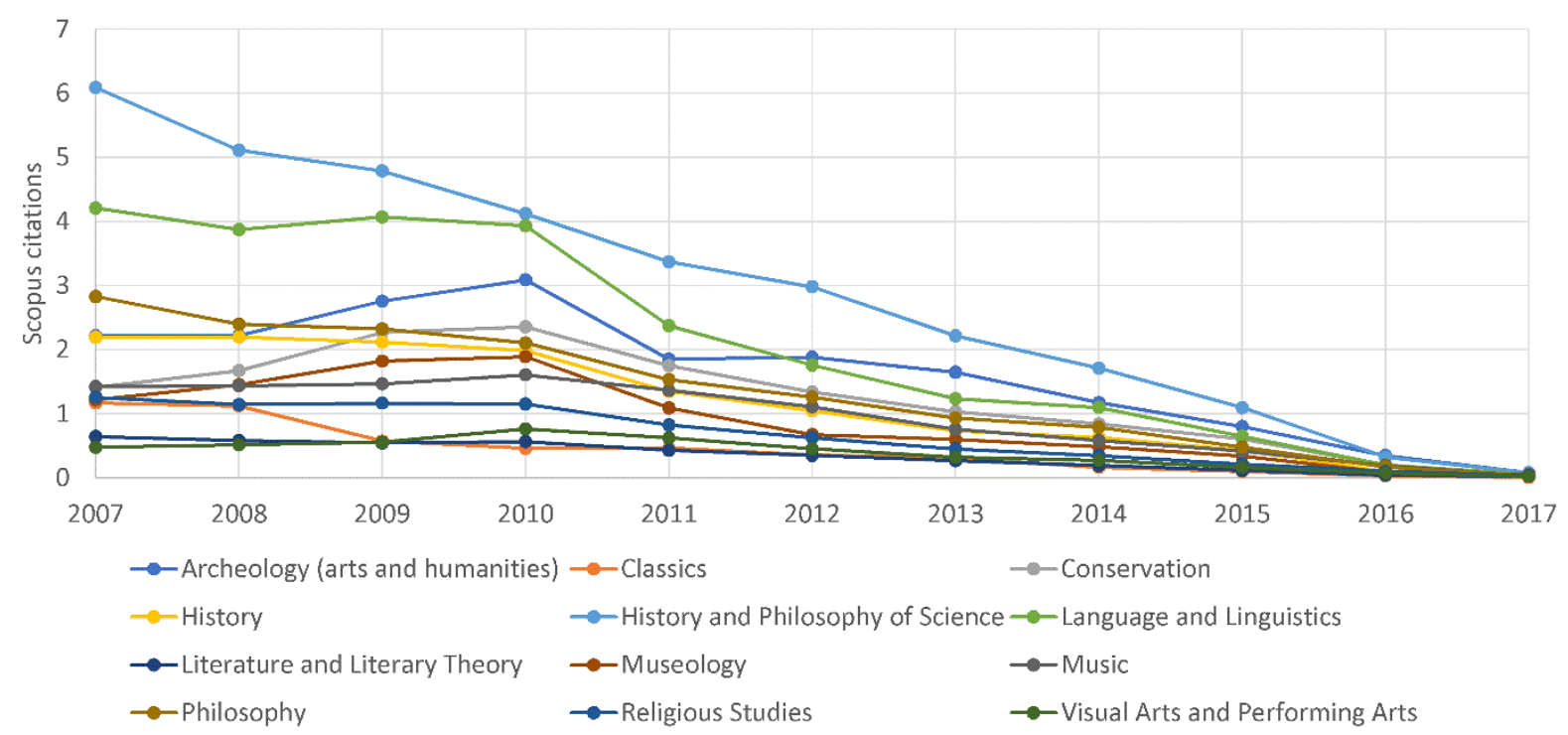

Figure 2. Geometric mean Scopus citation counts for each field and year.

Citations are slow to build up for arts and humanities articles (Figure 2) and Mendeley readers appear much more quickly (Figure 3). By 2007, the average number of Mendeley readers and Scopus citations per paper are similar (Table 1).

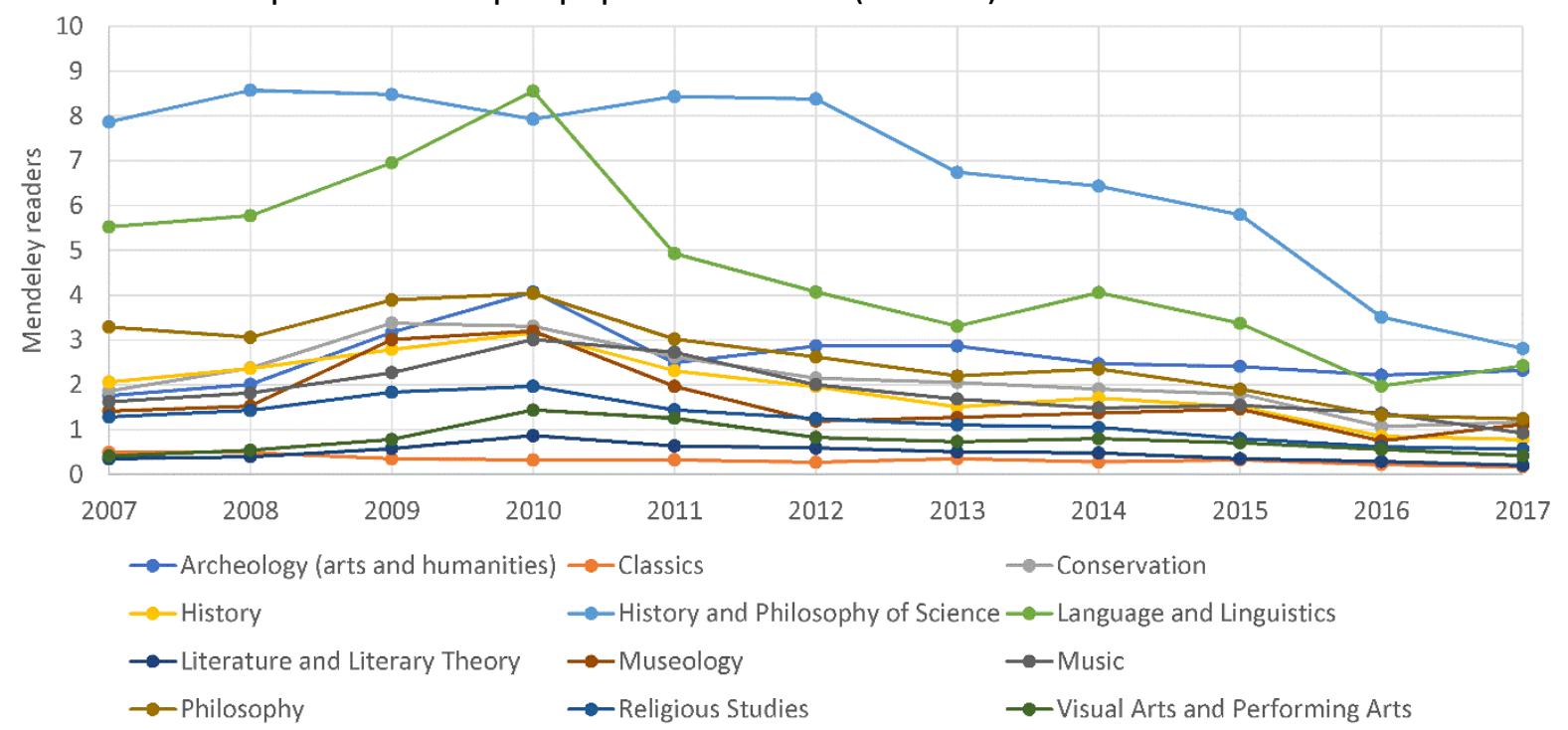

Figure 3. Geometric mean Mendeley reader counts for each field and year.

\section{Limitations}

The findings are limited by the Scopus subject categorisation scheme. They are based on journals and these may not always be categorised correctly. Moreover, the subject categories would not necessarily be recognised as coherent entities by field specialists. The trends over time can be misleading to some extent because of changes in the composition of each category as journals are added or removed. The Mendeley reader counts may also be underestimates for areas with many articles lacking DOls since, without DOls, the matching process does not necessarily find a Scopus article in Mendeley, especially if there are typos in the Scopus or Mendeley record. The percentage of articles with a DOI in Scopus has increased over time (Table A1) and so the Mendeley reader counts for earlier years may be underestimates compared to those of recent years. For the same reason (lost data), the 
correlations between Mendeley reader counts and Scopus citation counts may be underestimates for earlier years.

Some subjects contain magazines that are essentially uncitable (Thelwall, 2016a) but would inflate the correlation statistics by adding extra documents with no readers and no citations. To check for this, all articles in journals with at least $90 \%$ uncited articles were removed and the analysis repeated. The figure $90 \%$ is a conservative compromise since some articles in magazines are cited and the $90 \%$ threshold removes some academic journals, mostly non-English. The reduced set had 21\% fewer journals and $16 \%$ fewer articles (Table A2). The results (Table A3) were similar overall for the filtered data, with correlations falling on average by 0.040 (max: Conservation 0.114 and Museology 0.111; min: Archeology -0.001). This does not affect the conclusions.

\section{Discussion}

The correlations for long time periods (Table 1; Figure 1) are all higher than previous findings of 0.2-0.3 for five WoS humanities fields from 2008 (Linguistics; Philosophy; History; Literature; Religion) gathered four years later (Mohammadi \& Thelwall, 2014), suggesting that the previous findings are now out of date. Considering only the results from 2012, which gives four years to attract citations, all subject areas except Classics had a correlation above 0.4 , and some substantially higher (Figure 1). The most likely explanation for this is that Mendeley is more used in the humanities in 2017 than it was in 2012, giving higher average reader counts and more powerful correlations.

Comparing the magnitudes of the correlations for articles that were about ten years old at the time of data collection with equivalent figures from 2014 for 50 science and social science subcategories (Thelwall \& Sud, 2016, Figures 1-6), the arts and humanities correlations (Figure 1) tend to be lower overall (e.g., the social science correlations for the 2004 social sciences categories are mostly in the range $0.7-0.8$ ) and have a similar overall shape to the social sciences fields (Thelwall \& Sud, 2016, Figure 5). Thus, arts and humanities correlations follow broadly the same pattern as other fields.

The relative magnitudes of the Scopus citation counts (Figure 2) and Mendeley reader counts (Figure 3) are similar after ten years. Compared to other fields, the Scopus citation counts tend to be smaller and accumulate more slowly over time (Thelwall \& Sud, 2016, Figures 7-12) except for some social sciences categories, such as Cultural Studies and Archeology, that have humanities elements. The arts and humanities Mendeley reader counts (Figure 3 ) also tend to be a bit lower than the reader counts for science and social science categories (Thelwall \& Sud, 2016, Figures 13-18). Thus, whilst arts and humanities articles tend to attract fewer citations and readers than other academic fields, the overall balance between the two is similar.

To give an example of a specific paper with a relatively high citation count, the Cambridge Classical Journal article "Did the Greeks believe in their robots?" is from a low correlation, low citation, low readership field, Classics. This article has no Scopus or Google Scholar citations but 20 Mendeley readers (the highest for an uncited Classics article). The article is course reading for "Traces of the classic myth in English literature" at the University of Buenos Aires and has been cited by online BSc (USA) and MPhil (Australia) dissertations. Nearly all (17 out of 20) of the Mendeley readers were recorded as PhD students or academics and so its value is not primarily educational (cf. Thelwall, 2017). Readers' subjects recorded in Mendeley align broadly with the article topic (Arts \& Humanities: 14; Social Sciences: 4; Philosophy: 2). Thus, its lack of academic citations has occurred despite 
specialist academic interest in it. This article seems to have intrinsic interest in a way that is unlikely to further scholarship. Although this is an extreme case, it supports the common humanities claim that citation counts are not good at reflecting the value of humanities scholarship.

\section{Conclusions}

The results suggest, for the first time, that Mendeley reader counts can be used as an early impact indicator instead of citation counts in the arts and humanities. Nevertheless, since citation counts reflect the value of arts and humanities research less well than in other areas of academia, as judged by subject experts (HEFCE, 2015), Mendeley reader counts should be interpreted at least as cautiously as citation counts. For example, they may have some value at an aggregate level in some areas, if not for individual articles. As for all alternative scholarly indicators, Mendeley readership counts should be avoided in formal evaluations where stakeholders have the potential to manipulate them in advance (Wouters \& Costas, 2012).

As a side effect of the current research, the moderate and high correlations between Mendeley readers and Scopus citations are surprising in the context of the lack of a relationship between peer-judged quality and citation counts in the arts and humanities (HEFCE, 2015). Since Mendeley gives evidence of readership from people that do not necessarily cite a work, this suggests that academic audience breadth might not be a good indicator of the value of arts and humanities outputs. Alternatively, value might lie partly in the impact of arts and humanities research outside academia, or purely in the demonstration of expertise or credibility from the academic author. Whilst these issues probably apply to all areas of scholarship, they may well apply more strongly to the arts and humanities.

\section{References}

Basri, M., \& Patak, A. A. (2015). Exploring Indonesian students' perception on Mendeley Reference Management Software in academic writing. In 2nd International Conference on Information Technology, Computer, and Electrical Engineering (ICITACEE2015) (pp. 8-13). Los Alamitos: IEEE Press.

Belfiore, E., \& Upchurch, A. (2013). Introduction: Reframing the value debate for the humanities. In: Belfiore, E., \& Upchurch, A. (eds). Humanities in the twenty-first century: Beyond utility and markets. Berlin: Springer (pp. 1-13).

Borrego, Á., \& Fry, J. (2012). Measuring researchers' use of scholarly information through social bookmarking data: A case study of BibSonomy. Journal of Information Science, 38(3), 297-308.

Cho, J. (2017). A comparative study of the impact of Korean research articles in four academic fields using altmetrics. Performance Measurement and Metrics, 18(1), 3851.

Cobbledick, S. (1996). The information-seeking behavior of artists: Exploratory interviews. The Library Quarterly, 66(4), 343-372.

Cohen, J. (1988). Statistical power analysis for the behavioral sciences (2 ed). Hillsdale, NJ: Erlbaum.

Delgadillo, R., \& Lynch, B. P. (1999). Future historians: their quest for information. College \& Research Libraries, 60(3), 245-259. 
Earnshaw, R. A., Liggett, S., \& Excell, P. S. (2015). Evaluating the REF2014 results in art and design. In Internet Technologies and Applications (ITA2015). (pp. 514-519). Los Alamitos, CA: IEEE Press.

Erdt, M., Nagarajan, A., Sin, S. C. J., \& Theng, Y. L. (2016). Altmetrics: an analysis of the stateof-the-art in measuring research impact on social media. Scientometrics, 109(2), 11171166.

Fairclough, R., \& Thelwall, M. (2015a). More precise methods for national research citation impact comparisons. Journal of Informetrics, 9(4), 895-906. doi:10.1016/j.joi.2015.09.005

Fairclough, R. \& Thelwall, M. (2015b). National research impact indicators from Mendeley readers. Journal of Informetrics, 9(4), 845-859. doi:10.1016/j.joi.2015.08.003

Glänzel, W., \& Thijs, B. (2004). Does co-authorship inflate the share of self-citations? Scientometrics, 61(3), 395-404.

Gunn, W. (2013). Social signals reflect academic impact: What it means when a scholar adds a paper to Mendeley. Information standards quarterly, 25(2), 33-39.

Hammarfelt, B. (2014). Using altmetrics for assessing research impact in the humanities. Scientometrics, 101(2), 1419-1430.

Haustein, S., Larivière, V., Thelwall, M., Amyot, D., \& Peters, I. (2014). Tweets vs. Mendeley readers: How do these two social media metrics differ? IT-Information Technology, 56(5), 207-215.

HEFCE (2015). Supplementary Report II: Correlation analysis of REF2014 scores and metrics. http://www.hefce.ac.uk/pubs/rereports/year/2015/metrictide/

Hemphill, J. F. (2003). Interpreting the magnitudes of correlation coefficients. American Psychologist, 58(1), 78-80.

Hicks, D. (2004). The four literatures of social science. In: Handbook of quantitative science and technology research (pp. 473-496). Dordrecht, The Netherlands: Springer Netherlands.

Larivière, V., Archambault, É., Gingras, Y., \& Vignola-Gagné, É. (2006). The place of serials in referencing practices: Comparing natural sciences and engineering with social sciences and humanities. Journal of the Association for Information Science and Technology, 57(8), 997-1004.

Maflahi, N., \& Thelwall, M. (2016). When are readership counts as useful as citation counts? Scopus versus Mendeley for LIS journals. Journal of the Association for Information Science and Technology, 67(1), 191-199.

Maleki, A. (2015). Mendeley Readership Impact of Academic Articles of Iran. In: Proceedings of the 15th International Conference of the International Society for Scientometrics and Informetrics (ISSI2015) Istanbul, Turkey: Bogazici University (pp. 109-110).

Martin, K., \& Quan-Haase, A. (2016). The role of agency in historians' experiences of serendipity in physical and digital information environments. Journal of Documentation, 72(6), 1008-1026.

Merton, R. K. (1973). The sociology of science: Theoretical and empirical investigations. Chicago, IL: University of Chicago press.

Mohammadi, E., Thelwall, M., Haustein, S., \& Larivière, V. (2015). Who reads research articles? An altmetrics analysis of Mendeley user categories. Journal of the Association for Information Science and Technology, 66(9), 1832-1846. doi:10.1002/asi.23286 
Mohammadi, E., Thelwall, M. \& Kousha, K. (2016). Can Mendeley bookmarks reflect readership? A survey of user motivations. Journal of the Association for Information Science and Technology, 67(5), 1198-1209. doi:10.1002/asi.23477

Mohammadi, E. \& Thelwall, M. (2014). Mendeley readership altmetrics for the social sciences and humanities: Research evaluation and knowledge flows. Journal of the American Society for Information Science and Technology 65(8), 1627-1638.

Nederhof, A., Zwaan, R., De Bruin, R., \& Dekker, P. J. (1989). Assessing the usefulness of bibliometric indicators for the humanities and the social and behavioural sciences: $A$ comparative study. Scientometrics, 15(5-6), 423-435.

Nederhof, A. J. (2006). Bibliometric monitoring of research performance in the social sciences and the humanities: A review. Scientometrics, 66(1), 81-100.

Pooladian, A., \& Borrego, Á. (2017). Twenty years of readership of library and information science literature under Mendeley's microscope. Performance Measurement and Metrics, 18(1), 67-77.

Priem, J., Taraborelli, D., Groth, P., \& Neylon, C. (2010). Altmetrics: A manifesto. http://altmetrics.org/manifesto/

Thelwall, M. \& Delgado, M. (2015). Arts and humanities research evaluation: No metrics please, just data. Journal of Documentation, 71(4), 817-833. doi:10.1108/JD-02-20150028

Thelwall, M. \& Sud, P. (2016). Mendeley readership counts: An investigation of temporal and disciplinary differences. Journal of the Association for Information Science and Technology, 57(6), 3036-3050. doi:10.1002/asi.2355

Thelwall, M. (2016a). Are there too many uncited articles? Zero inflated variants of the discretised lognormal and hooked power law distributions. Journal of Informetrics, 10(2), 622-633. doi:10.1016/j.joi.2016.04.014

Thelwall, M. (2016b). Interpreting correlations between citation counts and other indicators. Scientometrics, 108(1), 337-347.

Thelwall, M. (2017). Why do papers have many Mendeley readers but few Scopus-indexed citations and vice versa? Journal of Librarianship \& Information Science, 49(2), 144151.

Thelwall, M. (in press). Does Mendeley provide evidence of the educational value of journal articles? Learned Publishing. Doi:10.1002/leap.1076

Vargas, S., Hristakeva, M., \& Jack, K. (2016). Mendeley: Recommendations for Researchers. In Proceedings of the 10th ACM Conference on Recommender Systems (pp. 365-365). New York, NY: ACM Press.

Waltman, L., van Eck, N. J., van Leeuwen, T. N., Visser, M. S., \& van Raan, A. F. (2011). Towards a new crown indicator: An empirical analysis. Scientometrics, 87(3), 467-481.

Waltman, L., \& van Eck, N. J. (2015). Field-normalized citation impact indicators and the choice of an appropriate counting method. Journal of Informetrics, 9(4), 872-894.

Wang, J. (2013). Citation time window choice for research impact evaluation. Scientometrics, 94(3), 851-872.

Wouters, P., \& Costas, R. (2012). Users, narcissism and control: tracking the impact of scholarly publications in the 21st century. In: Science and Technology Indicators 2012 (STI2012). Utrecht: The Netherlands: SURFfoundation (pp. 847-857).

Zahedi, Z., Costas, R., \& Wouters, P. (2015). Do Mendeley readership counts help to filter highly cited WoS publications better than average citation impact of journals (JCS)? In: Proceedings of the 15th International Conference of the International Society for 
Scientometrics and Informetrics (ISSI2015). Istanbul, Turkey: Bogazici University (pp. 110).

Zahedi, Z., Haustein, S. \& Bowman, T. (2014). Exploring data quality and retrieval strategies for Mendeley reader counts. Presentation at SIGMET Metrics 2014 workshop. http://www.slideshare.net/StefanieHaustein/sigme-tworkshopasist2014

Zoller, D., Doerfel, S., Jäschke, R., Stumme, G., \& Hotho, A. (2016). Posted, visited, exported: Altmetrics in the social tagging system BibSonomy. Journal of Informetrics, 10(3), 732749.

Zuccala, A., \& Guns, R. (2013). Comparing book citations in humanities journals to library holdings: Scholarly use versus perceived cultural benefit. In: Proceedings of the 14th International Conference of the International Society for Scientometrics and Informetrics (ISSI2013). (pp. 353-360). http://ebrp.elsevier.com/pdf/2012 Proposal6 Zuccala Guns.pdf

\section{Appendix}

Table A1. The percentage of journal articles with a DOI in Scopus in 2007 and the last complete year, 2016, by field.

\begin{tabular}{|l|r|r|r|}
\hline Field & $\mathbf{2 0 0 7}$ & $\mathbf{2 0 1 6}$ & \multicolumn{1}{|c|}{ Difference } \\
\hline Archeology (arts and humanities) & $64 \%$ & $23 \%$ & $41 \%$ \\
\hline Classics & $70 \%$ & $64 \%$ & $6 \%$ \\
\hline Conservation & $57 \%$ & $34 \%$ & $24 \%$ \\
\hline History & $44 \%$ & $27 \%$ & $17 \%$ \\
\hline History and Philosophy of Science & $21 \%$ & $9 \%$ & $12 \%$ \\
\hline Language and Linguistics & $36 \%$ & $26 \%$ & $10 \%$ \\
\hline Literature and Literary Theory & $77 \%$ & $41 \%$ & $36 \%$ \\
\hline Museology & $64 \%$ & $49 \%$ & $15 \%$ \\
\hline Music & $56 \%$ & $23 \%$ & $33 \%$ \\
\hline Philosophy & $37 \%$ & $24 \%$ & $14 \%$ \\
\hline Religious Studies & $47 \%$ & $27 \%$ & $20 \%$ \\
\hline Visual Arts and Performing Arts & $76 \%$ & $38 \%$ & $39 \%$ \\
\hline
\end{tabular}


Table A2. Number of journals and percentage rejected for having at least $90 \%$ uncited articles.

\begin{tabular}{|l|r|r|r|r|r|r|}
\hline Field & Journals & Rejected & \% & Articles & Removed & \% \\
\hline Archeology (arts and humanities) & 256 & 32 & $13 \%$ & 28380 & 1642 & $6 \%$ \\
\hline Classics & 110 & 20 & $18 \%$ & 8655 & 1095 & $13 \%$ \\
\hline Conservation & 62 & 15 & $24 \%$ & 8339 & 1390 & $17 \%$ \\
\hline History & 1053 & 190 & $18 \%$ & 90142 & 8047 & $9 \%$ \\
\hline History and Philosophy of Science & 173 & 19 & $11 \%$ & 28354 & 483 & $2 \%$ \\
\hline Language and Linguistics & 689 & 129 & $19 \%$ & 78369 & 7090 & $9 \%$ \\
\hline Literature and Literary Theory & 739 & 219 & $30 \%$ & 72918 & 22434 & $31 \%$ \\
\hline Museology & 43 & 12 & $28 \%$ & 4202 & 1072 & $26 \%$ \\
\hline Music & 136 & 31 & $23 \%$ & 15942 & 3294 & $21 \%$ \\
\hline Philosophy & 523 & 90 & $17 \%$ & 72534 & 6573 & $9 \%$ \\
\hline Religious Studies & 416 & 85 & $20 \%$ & 44004 & 6076 & $14 \%$ \\
\hline Visual Arts and Performing Arts & 452 & 138 & $31 \%$ & 52827 & 19042 & $36 \%$ \\
\hline Overall & $\mathbf{4 6 5 2}$ & $\mathbf{9 8 0}$ & $\mathbf{2 1 \%}$ & $\mathbf{5 0 4 6 6 6}$ & $\mathbf{7 8 2 3 8}$ & $\mathbf{1 6 \%}$ \\
\hline
\end{tabular}

Table A3. Fields, sample sizes and descriptive statistics after excluding articles in journals with at least $90 \%$ uncited articles.

\begin{tabular}{|l|r|r|r|r|r|}
\hline & $\begin{array}{l}\text { Minimum } \\
\text { articles } \\
\text { per year }\end{array}$ & $\begin{array}{l}\text { Average } \\
\text { articles } \\
\text { per } \\
\text { year }\end{array}$ & $\begin{array}{l}\text { Readers } \\
\text { /citations } \\
\text { correlation } \\
\mathbf{2 0 0 7}\end{array}$ & $\begin{array}{l}\text { leomean } \\
\text { citations } \\
\text { 2007 }\end{array}$ & $\begin{array}{l}\text { Geomean } \\
\text { readers } \\
\text { 2007 }\end{array}$ \\
\hline Archeology (arts and humanities) & 1565 & 2573 & 0.708 & 2.4 & 1.9 \\
\hline Classics & 399 & 744 & 0.369 & 1.4 & 0.6 \\
\hline Conservation & 261 & 660 & 0.615 & 3.2 & 4.7 \\
\hline History & 6563 & 7903 & 0.614 & 2.3 & 2.2 \\
\hline History and Philosophy of Science & 1130 & 2674 & 0.778 & 2.5 & 7.9 \\
\hline Language and Linguistics & 4583 & 6808 & 0.811 & 4.5 & 6.0 \\
\hline Literature and Literary Theory & 3217 & 4911 & 0.339 & 1.0 & 0.5 \\
\hline Museology & 173 & 304 & 0.616 & 3.4 & 4.2 \\
\hline Music & 837 & 1226 & 0.627 & 2.4 & 2.8 \\
\hline Philosophy & 4053 & 6318 & 0.616 & 3.1 & 3.7 \\
\hline Religious Studies & 2151 & 3680 & 0.472 & 1.5 & 1.6 \\
\hline Visual Arts and Performing Arts & 1714 & 3256 & 0.391 & 1.0 & 0.8 \\
\hline
\end{tabular}

